\title{
Experimental Research on the Mechanical Properties of Heated Granite after Rapid Cooling
}

\author{
Huifen Han, ${ }^{1,2}$ Junliang Peng, ${ }^{1,2}$ Yintong Guo $\mathbb{D},{ }^{3}$ Qiuyun He, ${ }^{4}$ Jun Zhou, ${ }^{3}$ \\ and Xinghao Gou ${ }^{1,2}$ \\ ${ }^{1}$ Engineering Technology Research Institute of PetroChina Southwest Oil and Gasfeld Company, Guanghan, \\ Sichuan 618300, China \\ ${ }^{2}$ Sichuan Key Laboratory of Shale Gas Evaluation and Production, Guanghan 618300, China \\ ${ }^{3}$ State Key Laboratory of Geomechanics and Geotechnical Engineering, Institute of Rock and Soil Mechanics, \\ Chinese Academy of Sciences, Wuhan 430071, China \\ ${ }^{4}$ Drilling and Production Technology Research Institute, CNPC Chuanqing Drilling Engineering Co.,Ltd., Chengdu, China \\ Correspondence should be addressed to Yintong Guo; ytguo@whrsm.ac.cn
}

Received 8 September 2020; Revised 15 July 2021; Accepted 9 August 2021; Published 11 September 2021

Academic Editor: Yuanxin Zhou

Copyright (c) 2021 Huifen Han et al. This is an open access article distributed under the Creative Commons Attribution License, which permits unrestricted use, distribution, and reproduction in any medium, provided the original work is properly cited.

Understanding the mechanical properties of the reservoir rock under different temperatures after rapid thermal cooling is necessary for safe and effective deep geoengineering applications, including deep mining projects, deep geological disposal of nuclear waste, and geothermal energy extraction. This paper is devoted to investigating the effect of rapid cooling on the mechanical behavior of the granite rock. At first, high-temperature heating was conducted. The 24 samples were divided into six groups and were heated at $100,200,300,400,500$, and $600^{\circ} \mathrm{C}$, and once they had reached the chosen temperature, they were immediately cooled with a cold water container, and the temperature of water in the pan was $25^{\circ} \mathrm{C}$. After the thermal treatment, the samples were measured using ultrasonic wave velocities, and then they were deformed under uniaxial and triaxial compression tests. The $P$-wave velocity, damage characteristics, stress-strain curves, compressive strength, and Young's modulus of the samples were presented considering different thermal temperatures. The results confirmed that the $P$-wave velocities of the samples generally decrease with temperature. $P$-wave velocity can indirectly reflect the damage of the rock structure. These changes represent a negative exponential relationship between $P$-wave velocity and hold temperature following cooling. As the samples experienced greater temperatures, the peak strength and elastic characteristics also significantly reduced. This is mainly due to thermally induced damage in the form of both intergranular and intragranular cracks. The stress-strain response revealed that the failure mode can change from brittle to quasi-brittle fracturing following treatment at increasingly greater temperatures.

\section{Introduction}

There are many important engineering applications in which rock is subjected to thermal loading. These include deep underground mining and deep drilling, underground storage of high-level nuclear waste, and geothermal energy extraction [1]. Geothermal energy has been identified as a renewable and reliable energy source; it has come into the stage of its rapid development $[1,2]$. The high-temperature rock mass (HDR) is more than $200^{\circ} \mathrm{C}$, which is directly extracted from the rock mass by artificial exploitation. It can be used to generate electricity and hot water. Hot dry rock
(HDR) geothermal energy is mainly stored in granite. To exploit HDR geothermal energy, we need a great amount of drilling in granite, especially deep boreholes that are used to form an artificial reservoir, mainly through hydraulic fracturing technologies [3]. In this process, a lot of cold water is injected and circulated through the artificial fractures in the geothermal reservoirs and eventually pumped back to the surface as steam [4]. Thermal stress caused by rapid heating or cooling is called thermal shock [5]. In this case, thermal stresses are generated by the transient distribution of temperatures in the rock. In the development of geothermal energy, due to the use of mud and circulating 
water, resulting in a very short time, the rock temperature decreases rapidly, so that the high-temperature rock showed thermal cracking, and the mechanical properties of rock mass changed [6].

On the one hand, it is advantageous for drilling; on the other hand, it is not conducive to the stability of the surrounding rock. At the same time, the construction of artificial reservoirs by using hydraulic fracturing technology is actually complex fracture dynamic thermal cracking in rock mass, and the fracture propagation direction is affected by rock thermal fracture propagation. These are related to the mechanical behavior of granite after water is cooled under high temperature, so it is necessary to have a clear understanding of the mechanical properties of high-temperature granite after water cooling. For example, if a cold temperature is suddenly applied to a warm or hot rock volume, a tensional tangential stress is generated at the surface of the rock where the cold temperature is applied, accompanied by compressive stresses behind the tension region.

In recent years, many scholars have conducted a lot of research studies on the physical and mechanical properties of granite under high temperature and have made many valuable research results. The physical and mechanical properties in granite rocks will change with high temperature such as elastic modulus reduction [5], permeability enhancement [7], and mechanical strength decrease [8]. The stress-strain characteristics of granite under normal temperature and high temperature were analyzed, and the phase characteristics of the heating treatment of different temperatures were analyzed. The results of the mechanical test and the results of the diffraction experiment were compared and analyzed [9]. Using the hightemperature and high-pressure triaxial test machine, the rock deformation test at $600^{\circ} \mathrm{C}$ and $6000 \mathrm{~m}$ of surrounding has been studied by using three $200 \mathrm{~mm} \times 400 \mathrm{~mm} \times 400 \mathrm{~mm}$ granite samples [9]. Through the real-time temperature after loading and high-temperature and SEM fracture tests under the uniaxial compression of two kinds of situations, the mechanical properties of granite under different temperatures were studied, and two kinds of uniaxial compressive strength, elastic modulus, and longitudinal wave velocity were analyzed [10]. Thermal deformation and failure characteristics of largesize granite specimens under high temperature and their thermal and mechanical parameters were systematically studied [11]. Using the high-precision micro-CT experiment system, the granite crystal grain size is 100 to $300 \mu \mathrm{m}$ irregular spatial structures [12]. The mechanical properties of watercooled granite samples under high temperatures within $600^{\circ} \mathrm{C}$ and the degradation mechanism of thermal cracking of watercooled granite were discussed [13].

To summarize, there is a consensus that, under high temperatures, rock mechanical properties change significantly [14]. However, due to differences in mineral composition and structure, including microfissures, the mechanical characteristics of rocks affected by temperature are complex $[15,16]$. Although much knowledge has been gained through theoretical and experimental studies, the research is yet to meet the demands of practical engineering, but there is less research on the mechanical properties of heated rocks after rapid thermal cooling. In this paper, a series of experiments were conducted on granite specimens by the MTS rock mechanics test system. Granite specimens were slowly heated to temperatures of 100, 200, 300, 400, 500 , and $600^{\circ} \mathrm{C}$ followed by rapid thermal cooling with a pan, and the temperature of water in the pan was $25^{\circ} \mathrm{C}$; $P$-wave velocity, microstructure damage, stress-strain curve, compressive strength, and elastic modulus after rapid thermal cooling were analyzed. The relationships of the indexes with temperature variation were analyzed and verified. The emphasis was given to the characterization of thermal shock cooling effects on the deformation, compressive strength properties, and failure mode. Through regression analysis, we obtained the corresponding formula, which provides a reference for deep drilling for geothermal resources.

\section{Experimental Design and Conditions}

2.1. Specimen Preparation. The granite samples were collected from Qinghai Province, China. The granite samples are taken from the same fresh block, and the samples show that there are no obvious fracture and pore characteristics. Granite samples appear white and gray in color. The average density of our granite samples is $2.61 \mathrm{~g} / \mathrm{cm}^{3}$ with around $1.24 \%$ porosity. The average $P$-wave velocity is $4277 \mathrm{~m} / \mathrm{s}$. According to ISRM suggested methods, all the tests were performed on cylindrical samples with $50 \mathrm{~mm}$ in diameter and $100 \mathrm{~mm}$ in height, with a surface parallelism value within $0.05 \mathrm{~mm}$ and surface flatness within $0.02 \mathrm{~mm}$. More than thirty samples were cored successfully. The main mineral compositions are shown in Table 1.

\subsection{Experimental Methods and Test Equipment. This paper} focused on the effects of rapid cooling on the mechanical properties of granite. The specimens were heated at different target temperatures $\left(100^{\circ} \mathrm{C}, 200^{\circ} \mathrm{C}, 300^{\circ} \mathrm{C}, 400^{\circ} \mathrm{C}, 500^{\circ} \mathrm{C}\right.$, and $600^{\circ} \mathrm{C}$, respectively) at a rate of $10^{\circ} \mathrm{C} / \mathrm{min}$ using a muffle furnace and held at each target temperature for 4 hours. After the hold period, the samples were removed from the furnace and immediately placed into a pan of room temperature water until they were cold to touch. $P$-wave velocities were tested before and after rapid thermal cooling with an RSM-SYS5-type ultrasonic detector. Ultrasound is one of the most important nondestructive testing techniques that can be applied to rocks as it is a fast, easy, and economical technique for both field and laboratory [15]. When the sound wave propagates in the medium, the information of the physical and mechanical properties is collected in the receiving wave. When the high-temperature granite meets the room temperature water, the temperature stress causes cracks to occur, and the internal structure can be changed. In order to understand the variation of the internal structure in the process of rapid thermal cooling, the change of $P$-wave velocity of each specimen was observed. After obtaining the ultrasonic measurements, we performed uniaxial or triaxial compression tests (confining pressure $=0 \mathrm{MPa}, 20 \mathrm{MPa}$, $40 \mathrm{MPa}$, and $60 \mathrm{MPa}$ ) using an MTS 815.03 rock mechanics testing machine. All tests were carried out according to the ISRM test standard. The predetermined confining pressure 
TABLe 1: The mineral composition of the test's granite.

\begin{tabular}{lcccc}
\hline \multirow{2}{*}{ Number } & \multicolumn{4}{c}{ Compositions } \\
& Quartz & Biotite & Albite & Microcline \\
\hline 1 & 19.97 & 9.27 & 37.79 & 32.98 \\
11 & 18.02 & 8.06 & 41.53 & 32.38 \\
16 & 22.19 & 6.01 & 40.77 & 31.03 \\
21 & 20.51 & 6.88 & 40.31 & 32.30 \\
26 & 19.52 & 9.22 & 36.59 & 34.66 \\
\hline
\end{tabular}

was applied to the sample followed by an axial load with a displacement rate of $0.003 \mathrm{~mm} / \mathrm{s}$, until the sample failure from which peak stress was obtained. Test results of the mechanical properties of the samples following heating to each target temperature and subsequent rapid cooling are shown in Table 2. All the tests were performed at room temperature and under dry conditions.

\section{Experimental Results and Analysis}

The outer surface of the heated samples following heating and rapid cooling is shown in Figure 1. The results show that, after rapid cooling, when the heating temperature is $100^{\circ} \mathrm{C}-400^{\circ} \mathrm{C}$, the surface color of the sample has no obvious change, and there is no obvious hot crack, as shown in Figures 1(a)-1(d). However, when the samples were heated to temperatures above $500^{\circ} \mathrm{C}$ and subsequently subjected to rapid cooling, the samples' surface exhibits microcracks, as shown in Figures 1(e) and 1(f). The microcracks are distributed irregularly.

3.1. Characteristics of P-Wave Velocity. Granite is composed of a variety of minerals; the physical and mechanical properties depend on mineral composition, the degree of cementation, and the development of pores and microcracks. Variations in $P$-wave velocity with different levels of heat treatment following rapid cooling are shown in Figure 2.

It can be seen that $P$-wave velocity decreases with each increment of heat treatment temperature. The specimen transforms into a state containing a large number of microcracks, which lead to the decrease of $P$-wave velocity. Therefore, the variation of $P$-wave velocity can reflect the growth of internal defects within the sample (such as microcracks and micropores); especially, microcracks of rocks are increasing significantly.

By regression analysis, the $P$-wave velocity and heated temperatures after rapid cooling conform to the following equation:

$$
\begin{aligned}
v_{p} & =5382.1 e^{-0.002 T}, \\
R^{2} & =0.9165 .
\end{aligned}
$$

Using methods of damage mechanics to research the questions of rock thermodynamics is a new development in rock mechanics [15]. After rapid cooling, various changes have taken place in the internal structure and material properties of granite. It also leads to the change of the refraction and diffraction of ultrasonic propagation. $P$-wave velocity can indirectly reflect the changes in rock mechanical properties. Based on the above analysis, the damage variable is defined by adopting the $P$-wave velocity as follows:

$$
D=1-\frac{V_{\mathrm{PT}}}{V_{P}},
$$

where $V_{\mathrm{PT}}$ stands for the $P$-wave velocity of the granite specimen after rapid cooling at different heated temperatures and $V_{P}$ stands for the $P$-wave velocity of the initial granite specimen before any heat treatment. Variations in granite damage with rapid cooling are shown in Figure 3. It can be seen that the damage variable increases gradually with increasing heat treatment. This shows that when the heat treatment temperature is low, there is little effect on the internal structure of the sample. There is a certain threshold temperature in which rock damage evolves, and the damage appears only when the temperature exceeds this threshold. With the increase of the amount of heat treatment, the damage variable also increases; it shows an approximate linear relationship. When the heating temperature reaches $600^{\circ} \mathrm{C}$, the damage variable is 0.7 . It can be deduced that a large number of microcracks have been produced within the internal structure of the sample.

\subsection{Strength and Deformation Characteristics of Samples.} The axial load and displacement obtained from uniaxial and triaxial compression tests are presented in Figure 4 for each of the samples that experienced heat treatment. Typically, from Figure 4(a), an elastic brittle behavior with a sharp postpeak softening response at small axial strains is observed. The stress-strain curves of granite after rapid cooling are compared with those obtained at room temperature; it can be seen that the brittleness of granite gradually decreases and the ductility gradually increases with a rise in heated temperature (Figure 4(a)). When the heat treatment is below $400^{\circ} \mathrm{C}$, the samples experience brittle failure, the peak deviatoric stress in samples treated to $400^{\circ} \mathrm{C}(181.61 \mathrm{MPa})$ is higher than $200^{\circ} \mathrm{C}(192.45 \mathrm{MPa})$ and $300^{\circ} \mathrm{C}(187.17 \mathrm{MPa})$, and the difference is $5.63 \%$. During the heating process from room temperature to $400^{\circ} \mathrm{C}$, the failure surfaces of many small fragments are observed, and the failure mode indicates greater brittleness. When the heated temperature exceeds $600^{\circ} \mathrm{C}$, the ductility of granite is enhanced, and the axial strain continues to increase after reaching the peak stress [17]. Under uniaxial compression, when the heat treatment temperature is between $400^{\circ} \mathrm{C}$ and $600^{\circ} \mathrm{C}$, the peak deviatoric stress is from 181.61 MPa to $95.23 \mathrm{MPa}$.

In Figures 4(b)-4(d), the results with confining pressures of 20,40 , and $60 \mathrm{MPa}$ are given. It can be seen from Figures $4(\mathrm{~b})-4(\mathrm{~d})$ that the peak deviatoric stress increases with the increase of confining pressure from $100^{\circ} \mathrm{C}$ to $600^{\circ} \mathrm{C}$. When the heating temperature is $100^{\circ} \mathrm{C}$, with increasing confining pressure from $0 \mathrm{MPa}$ to $60 \mathrm{MPa}$, the peak stresses are $210.91 \mathrm{MPa}(0 \mathrm{MPa}), 465.60 \mathrm{MPa}(20 \mathrm{MPa}), 629.54 \mathrm{MPa}$ $(40 \mathrm{MPa})$, and $656.34 \mathrm{MPa}(60 \mathrm{MPa})$. When the heating temperature is $400^{\circ} \mathrm{C}$, with increasing confining pressure from $0 \mathrm{MPa}$ to $60 \mathrm{MPa}$, the peak stress increased to $117.94 \%$ 
TABLE 2: Mechanical properties after heating $\left(100^{\circ} \mathrm{C}-600^{\circ} \mathrm{C}\right)$ and rapid cooling.

\begin{tabular}{|c|c|c|c|c|c|c|}
\hline No. & $\begin{array}{l}\text { Temperature } \\
\left({ }^{\circ} \mathrm{C}\right)\end{array}$ & $\begin{array}{l}\text { Confining pressure } \\
(\mathrm{MPa})\end{array}$ & $\begin{array}{l}P \text {-wave velocity } \\
\text { preheated }(\mathrm{m} / \mathrm{s})\end{array}$ & $\begin{array}{l}P \text {-wave velocity after water } \\
\text { cooling }(\mathrm{m} / \mathrm{s})\end{array}$ & $\begin{array}{c}\text { Deviatoric stress } \\
(\mathrm{MPa})\end{array}$ & $\begin{array}{l}\text { Young's modulus } \\
(\mathrm{GPa})\end{array}$ \\
\hline 91 & 25 & 0 & 4202 & 4225 & 245.39 & 52.19 \\
\hline 5 & 100 & 0 & 4057 & 3839 & 210.91 & 44.18 \\
\hline 10 & 200 & 0 & 4119 & 3679 & 192.45 & 39.03 \\
\hline 15 & 300 & 0 & 4348 & 3315 & 187.17 & 37.92 \\
\hline 20 & 400 & 0 & 4385 & 2797 & 181.61 & 34.79 \\
\hline 21 & 500 & 0 & 4289 & 2011 & 162.8 & 32.46 \\
\hline 26 & 600 & 0 & 4274 & 1790 & 95.23 & 18.16 \\
\hline 2 & 100 & 20 & 4034 & 4050 & 465.6 & 48.55 \\
\hline 7 & 200 & 20 & 4122 & 3430 & 447.47 & 46.5 \\
\hline 12 & 300 & 20 & 4172 & 3227 & 420.9 & 41.39 \\
\hline 17 & 400 & 20 & 4424 & 2768 & 375.79 & 37.97 \\
\hline 22 & 500 & 20 & 4446 & 2289 & 335.09 & 32.6 \\
\hline 27 & 600 & 20 & 4077 & 1357 & 309.37 & 28.19 \\
\hline 3 & 100 & 40 & 4403 & 4384 & 629.54 & 52.98 \\
\hline 8 & 200 & 40 & 4218 & 3770 & 601.03 & 48.39 \\
\hline 13 & 300 & 40 & 4423 & 3326 & 569.47 & 46.7 \\
\hline 18 & 400 & 40 & 4365 & 2700 & 528.68 & 41.39 \\
\hline 23 & 500 & 40 & 4290 & 2303 & 450 & 35.54 \\
\hline 28 & 600 & 40 & 4275 & 1729 & 394.6 & 28.49 \\
\hline 4 & 100 & 60 & 4217 & 4013 & 656.34 & 54.43 \\
\hline 9 & 200 & 60 & 4362 & 3850 & 667.82 & 47.6 \\
\hline 14 & 300 & 60 & 4298 & 3275 & 674.03 & 48.72 \\
\hline 19 & 400 & 60 & 4291 & 2701 & 592.05 & 42.97 \\
\hline 24 & 500 & 60 & 4384 & 2153 & 530.57 & 38.76 \\
\hline 29 & 600 & 60 & 4448 & 1354 & 506.61 & 30.45 \\
\hline
\end{tabular}

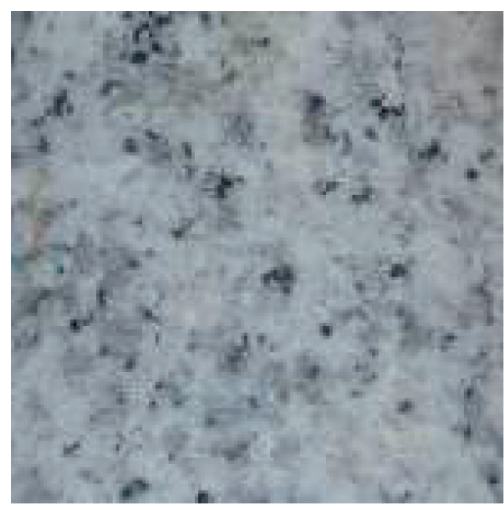

(a)

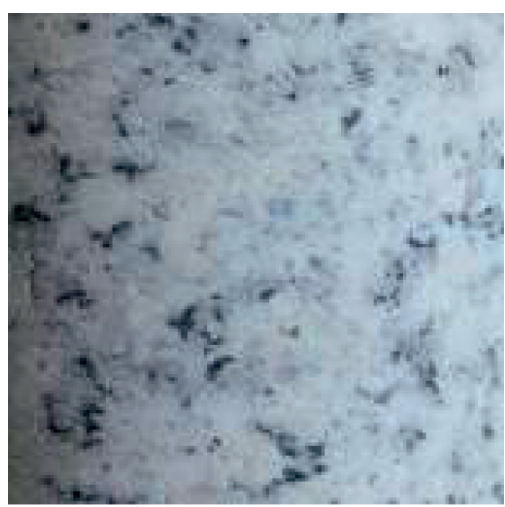

(d)

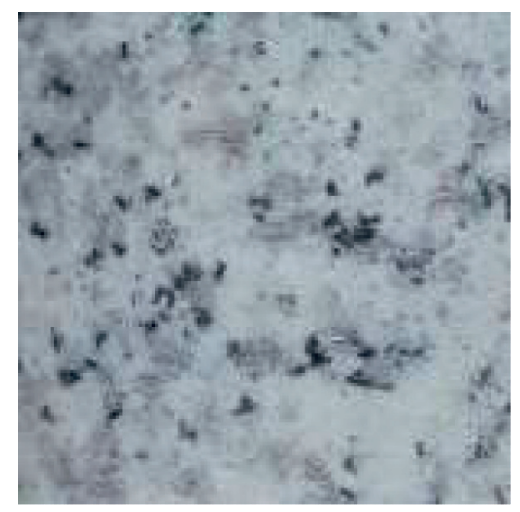

(b)

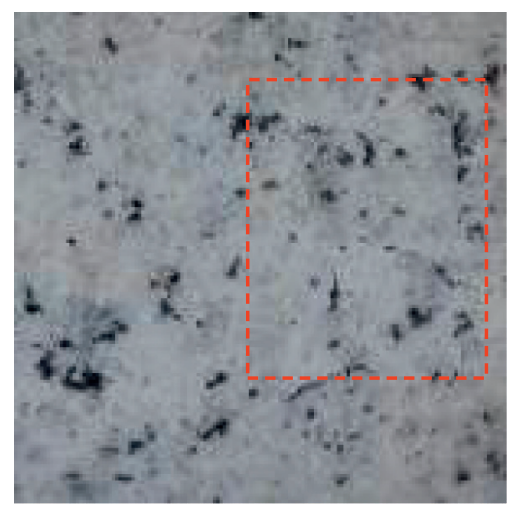

(e)

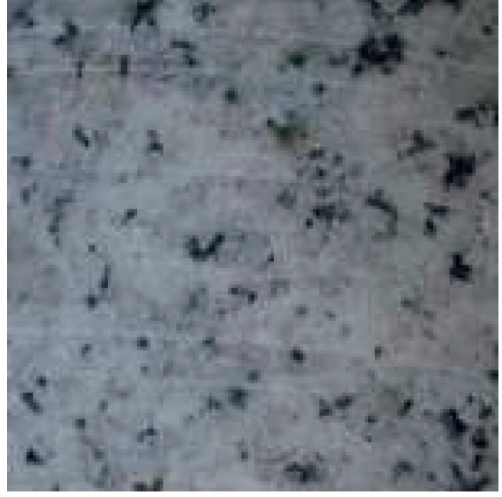

(c)

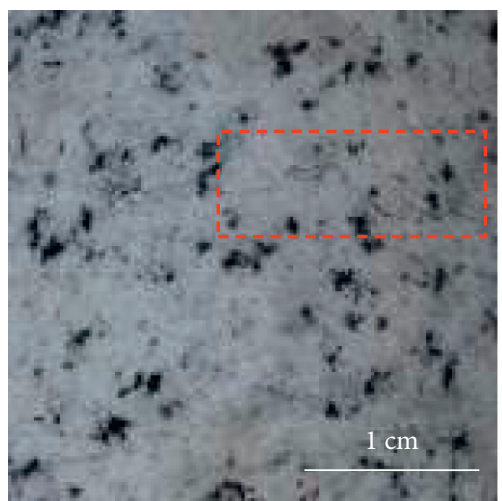

(f)

Figure 1: The surface of heated granite specimens after rapid thermal cooling. (a) $100^{\circ} \mathrm{C}$. (b) $200^{\circ} \mathrm{C}$. (c) $300^{\circ} \mathrm{C}$. (d) $400^{\circ} \mathrm{C}$. (e) $500^{\circ} \mathrm{C}$. (f) $600^{\circ} \mathrm{C}$. 


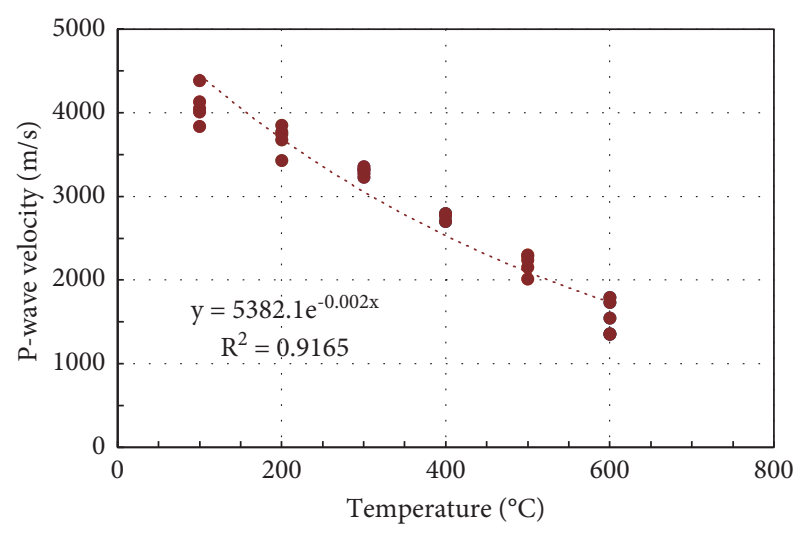

Figure 2: Variations in $P$-wave velocity with different levels of heat treatment and rapid cooling.

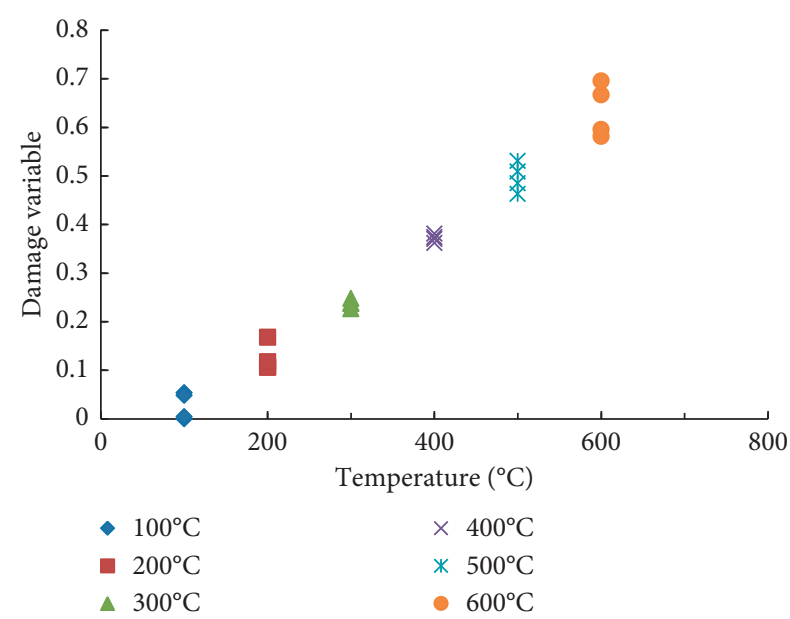

FIgURE 3: Variations in the damage variable with changes in heat treatment temperature.

(20 MPa), 213.14\% (40 MPa), and 259.05\% (60 MPa). In samples heat-treated to $600^{\circ} \mathrm{C}$, when the confining pressure increased from $0 \mathrm{MPa}$ to $60 \mathrm{MPa}$, the peak stress also increased to $245.88 \%$ (20 MPa), 356.39\% (40 MPa), and $495.01 \%$ $(60 \mathrm{MPa})$. The mechanical properties of granite are much more damaged due to temperature stress. In Figure 5, the peak deviatoric stress-heated temperature curves of granite after rapid thermal cooling are shown. Under the condition of $20 \mathrm{MPa}$, when the heating temperature is from $100^{\circ} \mathrm{C}$ to $600^{\circ} \mathrm{C}$, the peak deviatoric stress decreases from $465.60 \mathrm{MPa}$ to $309.37 \mathrm{MPa}$, with a decrease of $33.60 \%$; under the condition of $40 \mathrm{MPa}$, when the heating temperature is from $100^{\circ} \mathrm{C}$ to $600^{\circ} \mathrm{C}$, the peak deviatoric stress decreases from $629.54 \mathrm{MPa}$ to $394.60 \mathrm{MPa}$, with a decrease of $37.30 \%$; under the condition of $60 \mathrm{MPa}$ confining pressure, when the heating temperature is from $100^{\circ} \mathrm{C}$ to $600^{\circ} \mathrm{C}$, the peak deviatoric stress decreases from $656.34 \mathrm{MPa}$ to $506.61 \mathrm{MPa}$, with a decrease of $22.80 \%$.

The elastic modulus is considered to be among the main mechanical properties which is a prerequisite for the analysis and design of geological engineering projects [18]. Figure 6 illustrates variations in Young's modulus for our heattreated samples. It can be shown that elastic modulus generally increases with confining pressure for all samples but decreases for each level of heat treatment. Young's modulus shows a gentle decrease from room temperature to rapid cooling of $600^{\circ} \mathrm{C}$ and decreases from $52.19 \mathrm{GPa}$ to $18.16 \mathrm{GPa}$ under uniaxial conditions, showing a $65.20 \%$ decrease.

Rock strength depends partly on the cohesion of the rock and the internal friction between the rock particles. Cohesion is caused by cement between mineral particles. The strength of the shale rock mainly depends on the cohesion and internal friction. Under the condition of high-temperature rapid thermal cooling, shale can reach a temperature difference of over $200^{\circ} \mathrm{C}$, which will reduce the rock cohesion and internal friction, resulting in crack damage and causing the decrease of rock strength.

The Mohr-Coulomb criterion is the most common failure criterion for brittle rocks [19-21]. It can provide constant values of friction angle $(u)$ and cohesion $(c)$, which are significant for numerical simulation and improving the understanding of the rocks' mechanical properties. Therefore, in this paper, the MC failure criterion was used for the laboratory data in order to determine friction angle and cohesion under the condition of high-temperature rapid thermal cooling.

The linear Mohr-Coulomb failure criterion can be written as equation (3) in Mohr stress space or equation (4) in the principal stress space [21]:

$$
\begin{aligned}
\tau & =c+\sigma_{n} \tan \phi, \\
\sigma_{1} & =m \sigma_{3}+C_{0},
\end{aligned}
$$

where $\tau$ is the shear stress, $\sigma_{n}$ is the normal stress, $c$ is the cohesion, $\phi$ is the friction angle, $\sigma_{1}$ is the major principal stress, $\sigma_{3}$ is the minor principal stress, $m$ is the line slope, and $C_{0}$ is the uniaxial compressive strength. Equations (3) and (4) both have a linear relationship in the $\tau-\sigma_{n}$ and $\sigma_{1}-\sigma_{3}$ planes, respectively. After transformation, equation (5) can be obtained:

$$
\begin{aligned}
\phi & =\arcsin \frac{m-1}{m+1}, \\
c & =\sigma_{0} \frac{1-\sin \phi}{2 \cos \phi} .
\end{aligned}
$$

The friction angle and cohesion can be obtained using equations (5) and (6). Based on the test data (as seen in Table 2), the friction angle and cohesion after heating and rapid cooling are obtained and presented in Table 3. Figure 7 gives the maximum principal stress-confining pressure curves of our samples after heating and cooling at different maximum temperatures. As seen in Table 3, with the increasing levels of heat treatment, the cohesive force of the granite rock decreases gradually. There is a significant diminution of frictional coefficient due to the increase of temperature. When the virgin samples were tested, the cohesion was $33.91 \mathrm{MPa}$, but after heat treatment to $600^{\circ} \mathrm{C}$, the cohesion decreased to $16.52 \mathrm{MPa}$, showing a $51.30 \%$ decrease. 


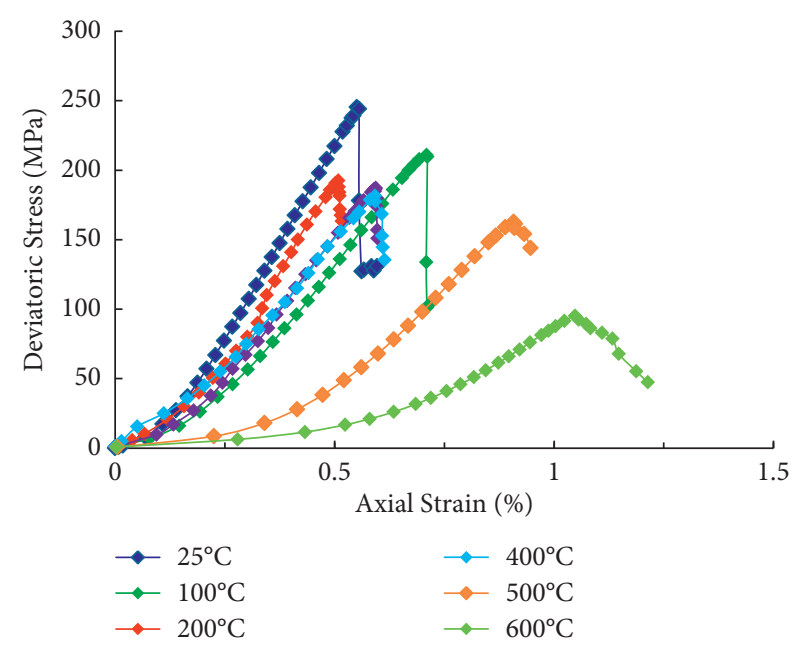

(a)

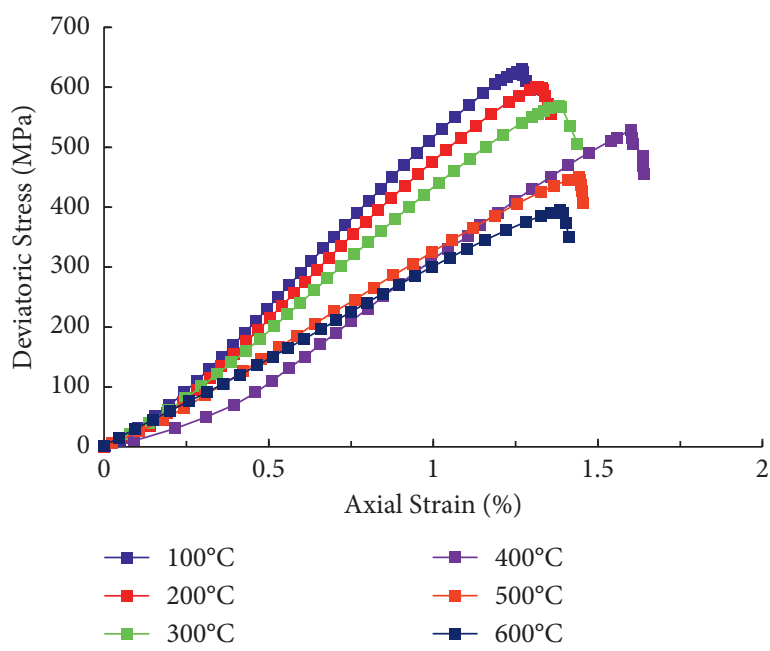

(c)

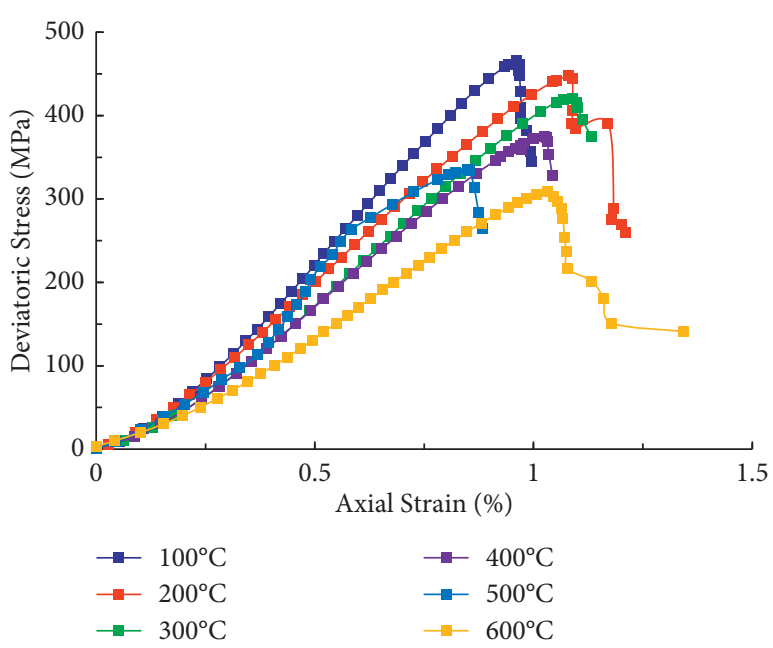

(b)

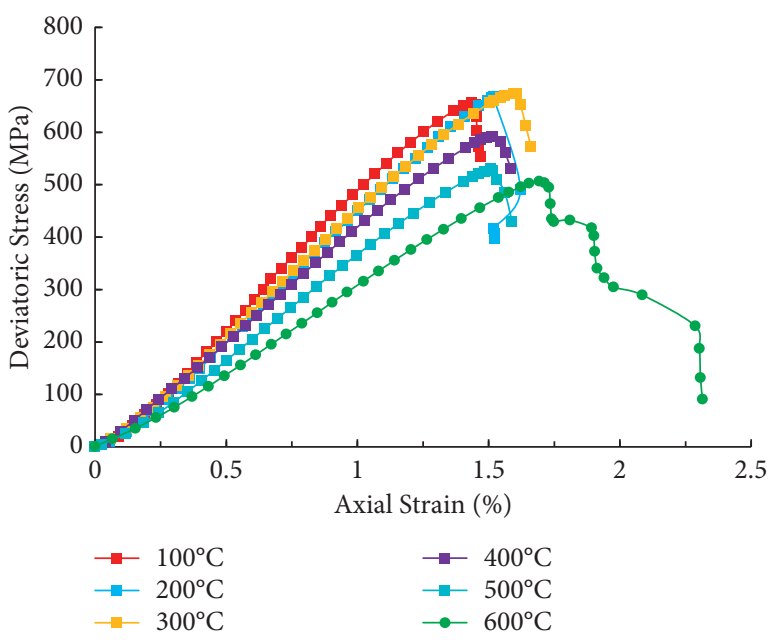

(d)

FIGURE 4: Complete stress-strain curves as a function of increasing levels of confining pressure and for each heat treatment temperature. (a) $\sigma_{3}=0 \mathrm{MPa}$. (b) $\sigma_{3}=20 \mathrm{MPa}$. (c) $\sigma_{3}=40 \mathrm{MPa}$. (d) $\sigma_{3}=60 \mathrm{MPa}$.

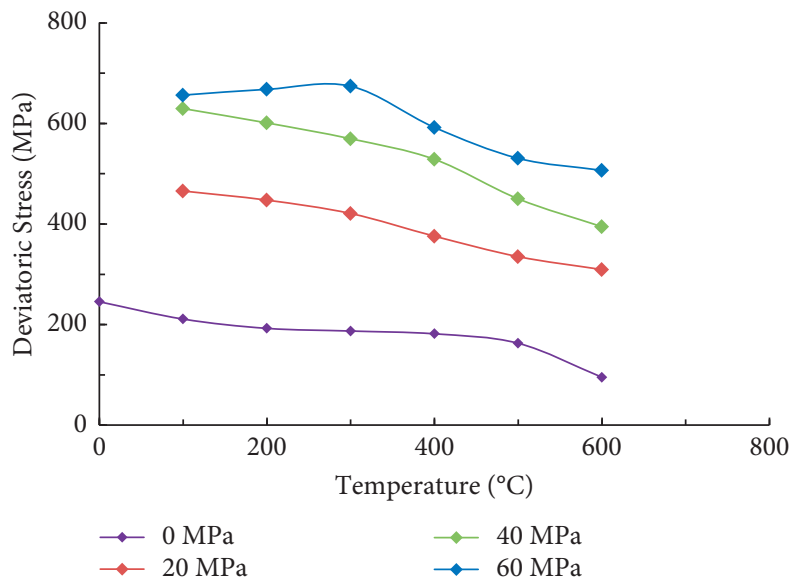

Figure 5: Peak deviatoric stress for each heat-treated sample and at different levels of confinement. 


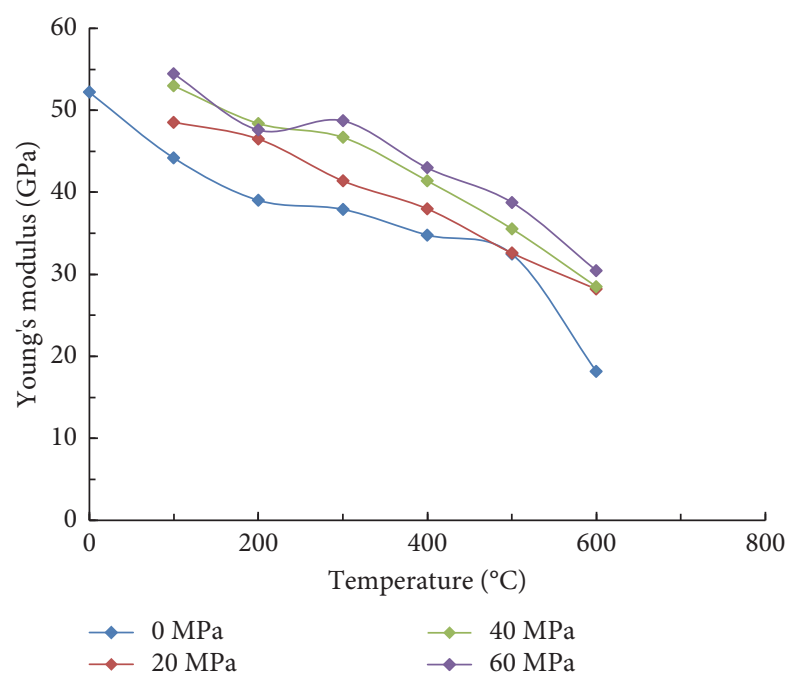

FIgURE 6: Young's modulus of the heat-treated samples as a function of different levels of confining pressure.

Table 3: The cohesion and internal friction of the sample.

\begin{tabular}{lccc}
\hline$T\left({ }^{\circ} \mathrm{C}\right)$ & Cohesion $(\mathrm{MPa})$ & Internal friction angle $\left({ }^{\circ}\right)$ & Correlation coefficient \\
\hline 100 & 33.91 & 54.35 & 0.89 \\
200 & 30.55 & 54.77 & 0.93 \\
300 & 29.92 & 54.54 & 0.96 \\
400 & 31.02 & 52.28 & 0.96 \\
500 & 29.51 & 50.14 & 0.97 \\
600 & 16.52 & 51.74 & 0.95 \\
\hline
\end{tabular}

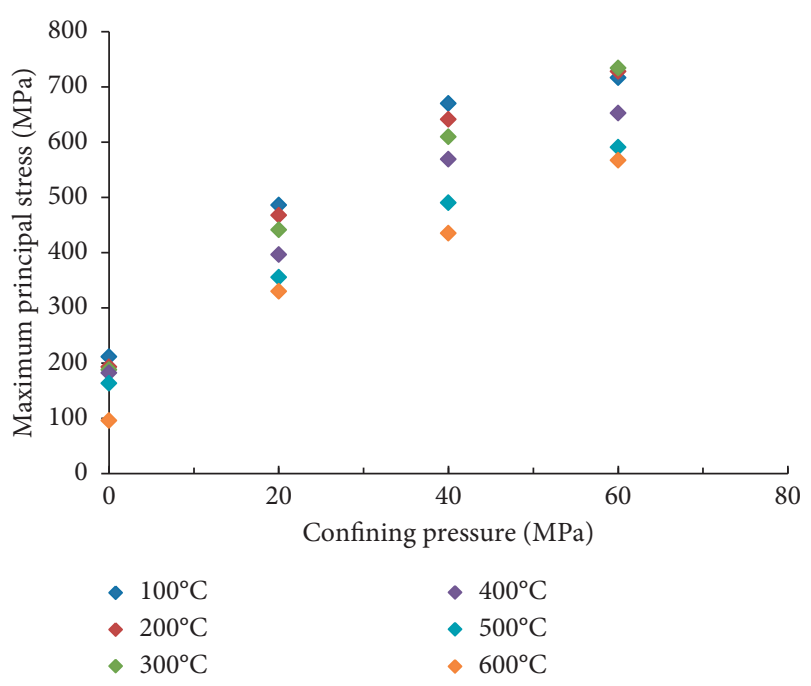

FIGURE 7: Maximum principal stress-confining pressure curves of granite after rapid thermal cooling with different heated temperatures.

3.3. Mechanical and Fracture Characteristics of Samples. The macrofracture of rocks is mainly due to the expansion and growth of internal microcracks. The thermal treatment of the granite samples influences their mechanical properties. Granite samples experienced both brittle and semibrittle fracture and plastic deformation.
In Figure 8, the tested samples after uniaxial and triaxial compression tests are shown. In general, a brittle splitting failure is observed in uniaxial compression tests, with a plurality of vertical split cracks, and the rupture plane is parallel to the axial loading direction. There are 3 types of failure mode: burst instability, quasi-burst failure, and progressive failure. The sudden instability is shown by the sudden decrease of stress and with a sharp crack. The stress-strain curve is shown as a vertical drop; the quasi-burst instability is shown as the stress decreases rapidly, and the failure has a large sound, but there is no sudden instability; progressive failure showed that the stress slowed down or did not fall, the rupture had only a minor sound, and the stress-strain curve was formed.

In triaxial compression tests, the rock failure is characterized by a localized shear band whose inclination increases with confining pressure. The specimen has a brittle fracture surface, and the properties of the main fracture surface differ from those of confining pressure. Furthermore, with increasing confining pressure and heated temperature, a gradual reduction was observed in the rupture angle with respect to the minor principal stress direction, and the fracture surface was more rough and destroyed with smaller fragments. Granite contains a variety of mineral particles with different coefficients and anisotropic expansion, caused by thermal expansion of the cross grain boundary coordination, and the rock produces tiny cracks or primary cracks, widened or through. 

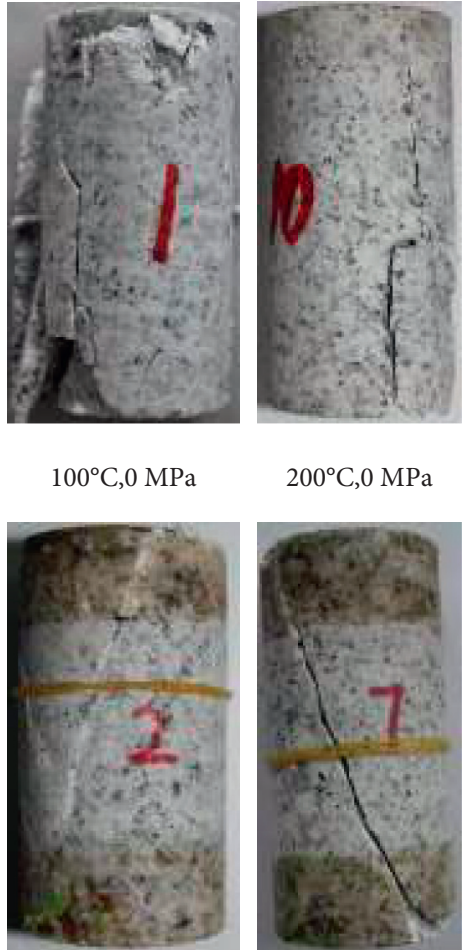

$200^{\circ} \mathrm{C}, 0 \mathrm{MPa}$

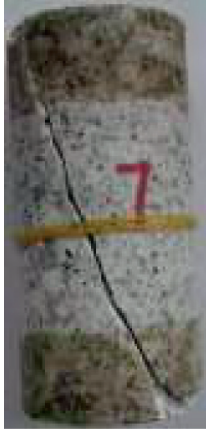

$200^{\circ} \mathrm{C}, 20 \mathrm{MPa}$

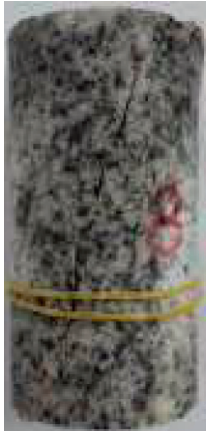

$200^{\circ} \mathrm{C}, 40 \mathrm{MPa}$

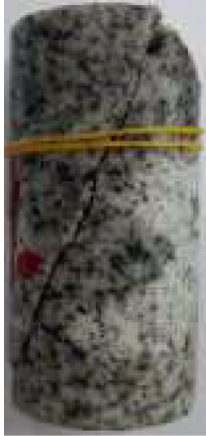

$200^{\circ} \mathrm{C}, 60 \mathrm{MPa}$
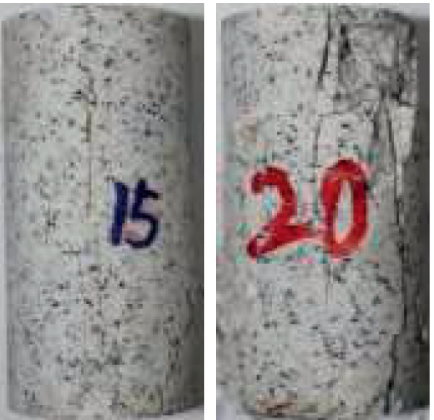

$300^{\circ} \mathrm{C}, 0 \mathrm{MPa}$

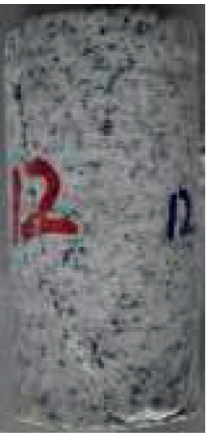

$300^{\circ} \mathrm{C}, 20 \mathrm{MPa}$

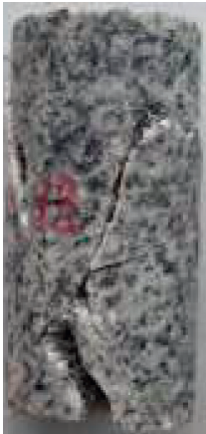

$300^{\circ} \mathrm{C}, 40 \mathrm{MPa}$

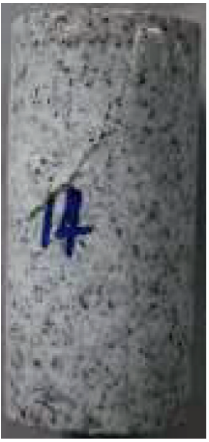

$300^{\circ} \mathrm{C}, 60 \mathrm{MPa}$

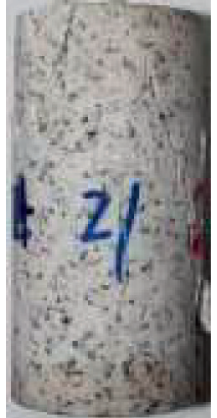

$500^{\circ} \mathrm{C}, 0 \mathrm{MPa}$

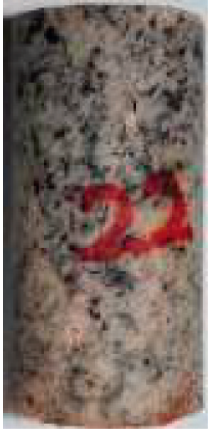

$500^{\circ} \mathrm{C}, 20 \mathrm{MPa}$

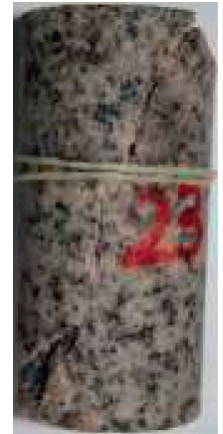

$500^{\circ} \mathrm{C}, 40 \mathrm{MPa}$

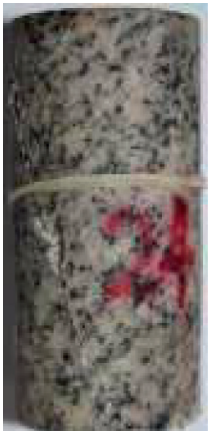

$500^{\circ} \mathrm{C}, 60 \mathrm{MPa}$

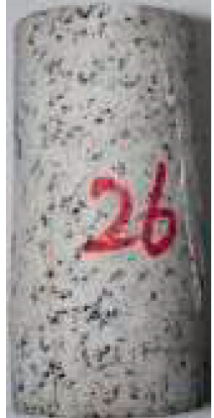

$600^{\circ} \mathrm{C}, 0 \mathrm{MPa}$

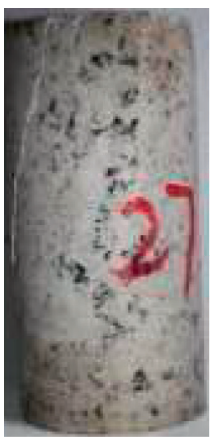

$600^{\circ} \mathrm{C}, 20 \mathrm{MPa}$

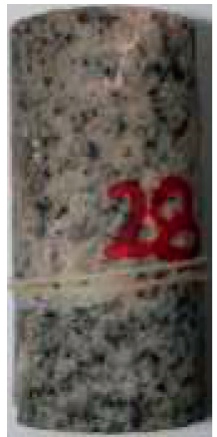

$600^{\circ} \mathrm{C}, 40 \mathrm{MPa}$

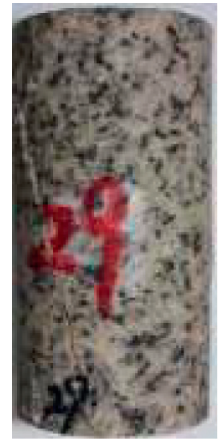

$600^{\circ} \mathrm{C}, 60 \mathrm{MPa}$

Figure 8: Tested granite samples after uniaxial and triaxial compression tests.

\section{Discussion}

Mechanical property estimation of rocks is considered to be the most important component in any geological engineering project $[22,23]$. With the increase of mining and oil drilling depth, more and more rock mechanics problems related to high temperature are encountered. Also, rapid thermal cooling occurs in several important mining 
and geotechnical engineering applications, including the ventilation of mines at depth and deep drilling in dry hot rocks. Due to the use of slurry and drilling fluid, the temperature of surrounding rock decreases rapidly, resulting in thermal fracture, and the mechanical properties of granite rock mass may be altered. The $P$-wave velocity, elastic modulus, and peak stress decrease gradually with the increase of the heated temperature. And the higher the heated temperature, the greater the decrease. $P$-wave velocity can indirectly reflect the changes in mechanical properties $[14,16,17,24-27]$. This is due to the minerals in which physical and chemical changes take place. These mineral particles have different physical and mechanical properties, thermal cracking occurs at the interface between quartz and mica, which is mainly caused by thermal expansion. Due to the difference of thermal expansion, the thermal crack is usually at the boundary of the mineral particle and extends along the boundary of the particle. These results indicate the dependency of mineralogical composition and grain size distribution on the temperature-dependent mechanical behavior. Still, there would be some thermal cracking during cooling [25], the cracks around the granite crystal grains are formed, and the further development cracks are formed by the thermal cracks. When the sample is heated or watercooled rapidly at a high speed, it is necessary to produce thermal shock in the rock mass. When the cold drilling mud or circulating cold water for geothermal development is injected into the hot dry rock, it may cause local hot dry rock cracking, resulting in the change of mechanical properties. Due to thermal expansion between the minerals, granite will produce microcracks, and the higher the temperature is, the larger the thermal stress, microcracks are mostly caused by the propagation of main macrocracks.

\section{Conclusions}

The effects of rapid cooling on the mechanical behavior of Qinghai granite from China have been investigated through a series of uniaxial and triaxial compression tests as well as characterization from $P$-wave velocities. These tests allowed examination of microstructure damage, stress-strain curves, compressive strength, and elastic modulus after heating and rapid cooling. It is verified that high temperature after rapid cooling is a key effect on the physical and mechanical characteristics of rocks. Some interesting conclusions can be drawn as follows:

(1) Rapid cooling of our granite to temperatures above $400^{\circ} \mathrm{C}$ causes the initiation of thermal cracks, which may extend to visible macrocracks. The variation of $P$-wave velocities reflects the growth of internal defects within the samples (such as microcracks). We report a negative exponential relationship between $P$-wave velocity and heat treatment temperature.

(2) In general, as a result of the heat treatment, our granite's compressive strength and elastic modulus reduce. Under uniaxial compression, an elastic brittle behavior of granite with a sharp postpeak softening response can be observed which occurred at small axial strains. When the heat treatment temperature increased from $400^{\circ} \mathrm{C}$ to $600^{\circ} \mathrm{C}$, the peak stress decreased by $47.60 \%$.

(3) Under uniaxial compression, the elastic modulus of granite decreases, when comparing the nonheattreated samples to the samples heat-treated to $600^{\circ} \mathrm{C}$, from $52.19 \mathrm{GPa}$ to $18.16 \mathrm{GPa}$, showing a $65.20 \%$ decrease.

(4) With the increase of heated temperature for rapid cooling, the cohesive force decreases. There is a significant diminution of frictional coefficient due to the increase of heated temperature. When the temperature is $25^{\circ} \mathrm{C}$, the cohesion is $33.91 \mathrm{MPa}$, and when the heated temperature is $600^{\circ} \mathrm{C}$ with rapid cooling, the cohesion decreases to $16.52 \mathrm{MPa}$, showing a $51.30 \%$ decrease.

\section{Data Availability}

The data used or analyzed during the current study are available from the corresponding author upon reasonable request.

\section{Conflicts of Interest}

The authors declare that there are no conflicts of interest regarding the publication of this paper.

\section{Acknowledgments}

This research was supported by the Preliminary Evaluation Project of Natural Gas Development in 2019 of PetroChina Co., Ltd., and Science and Technology Project of Southwest Oil and Gas Field Branch (20200302-17). The authors would like to express their greatest gratitude for their generous support.

\section{References}

[1] K. Kim, J. Kemeny, and M. Nickerson, "Effect of rapid thermal cooling on mechanical rock properties," Rock Mechanics and Rock Engineering, vol. 47, no. 6, pp. 2005-2019, 2014.

[2] T. Kohl, K. F. Evansi, R. J. Hopkirk, and L. Rybach, "Coupled hydraulic, thermal and mechanical considerations for the simulation of hot dry rock reservoirs," Geothermics, vol. 24, no. 3, pp. 345-359, 1995.

[3] S. Saito, "Recent geothermal well drilling technologies in Kakkonda and Matsukaw," Geothermal Resources Council Bulletin, no. 7, pp. 166-174, 1991.

[4] W. G. P. Kumari, P. G. Ranjith, M. S. A. Perera et al., "Mechanical behaviour of Australian Strathbogie granite under in-situ stress and temperature conditions: an application to geothermal energy extraction," Geothermics, vol. 65, pp. 44-59, 2017.

[5] M. Z. Lin, Thermal Physics of Rock and its Application, Chongqing University Press, Chongqing, China, 1991.

[6] B. Xi and Y. Zhang, "Experimental research on mechanical properties of water-cooled granite under high temperatures with-in $600^{\circ} \mathrm{C}$," Chinese Journal of Rock Mechanics and Engineering, vol. 29, no. 5, pp. 892-898, 2010. 
[7] C. David, B. Menéndez, and M. Darot, "Influence of stressinduced and thermal cracking on physical properties and microstructure of La Peyratte granite," International Journal of Rock Mechanics and Mining Sciences, vol. 36, no. 4, pp. 433-448, 1999.

[8] F. E. Heuze, "High-temperature mechanical, physical and Thermal properties of granitic rocks- A review," International Journal of Rock Mechanics and Mining Science \& Geomechanics Abstracts, vol. 20, no. 1, pp. 3-10, 1983.

[9] X. Xu, F. Gao, Y. Gao, and H. Xie, "Effect of high temperatures on the mechanical characteristics and crystal structure of granite," Journal of China University of Mining and Technology, vol. 37, no. 3, pp. 402-406, 2008.

[10] Z. Zhang, F. Gao, and X. Xiao-li, "Experimental study of temperature effect of mechanical properties of granite," Rock and Soil Mechanics, vol. 32, no. 8, pp. 2346-2352, 2011.

[11] Z.-J. Wan, Y.-S. Zhao, F. Dong, and Z. Feng, "Experimental study on mechanical characteristics of granite under high temperatures and triaxial stresses," Chinese Journal of Rock Mechanics and Engineering, vol. 27, no. 1, pp. 72-77, 2008.

[12] Y. Zhao, Z. Feng, B. Xi, Z. Wan, D. Yang, and W. Liang, "Deformation and instability failure of borehole at high temperature and high pressure in Hot Dry Rock Exploitation," Renewable Energy, vol. 77, pp. 159-165, 2015.

[13] B. Xi and Y. Zhao, "Experimental study of thermo physicomechanical property of drilling surrounding rock in granite under high temperature and high pressure," Chinese Journal of Rock Mechanics and Engineering, vol. 29, no. 6, pp. 12461253, 2010.

[14] S. Chaki, M. Takarli, and W. P. Agbodjan, "Influence of thermal damage on physical properties of a granite rock: porosity, permeability and ultrasonic wave evolutions," Construction and Building Materials, vol. 22, no. 5, pp. 1456-1461, 2008.

[15] S. Liu and J. Xu, "An experimental study on the physicomechanical properties of two post-high-temperature rocks," Engineering Geology, vol. 185, pp. 63-70, 2015.

[16] W. Zhang, Q. Sun, S. Hao, J. Geng, and C. Lv, "Experimental study on the variation of physical and mechanical properties of rock after high temperature treatment," Applied Thermal Engineering, vol. 98, pp. 1297-1304, 2016.

[17] A. Castagna, A. Ougier-Simonin, P. M. Benson et al., "Thermal damage and pore pressure effects of the brittleductile transition in comiso limestone," Journal of Geophysical Research: Solid Earth, vol. 123, no. 9, pp. 7644-7660, 2018.

[18] E. M. Winkler, Stone in Architecture. Properties, Durability, Springer-Verlag, Berlin, 3a edition, 1997.

[19] B. Brady and E. T. Brown, Rock Mechanics for Underground Mining, Springer, vol. 3, p. 628, New York, NY, USA, 2006.

[20] K. Mogi, Experimental Rock Mechanics, CRC Press, London, UK, 2007.

[21] P. Zhang, B. Mishra, and K. A. Heasley, "Experimental investigation on the influence of high pressure and high temperature on the mechanical properties of deep reservoir rocks," Rock Mechanics and Rock Engineering, vol. 48, no. 6, pp. 2197-2211, 2015.

[22] R. Costamagna, J. Renner, and O. T. Bruhns, "Relationship between fracture and friction for brittle rocks," Mechanics of Materials, vol. 39, no. 4, pp. 291-301, 2007.

[23] K. Diamantis, E. Gartzos, and G. Migiros, "Study on uniaxial compressive strength, point load strength index, dynamic and physical properties of serpentinites from Central Greece: test results and empirical relations," Engineering Geology, vol. 108, no. 3-4, pp. 199-207, 2009.
[24] J. Browning, P. Meredith, and A. Gudmundsson, "Coolingdominated cracking in thermally stressed volcanic rocks," Geophysical Research Letters, vol. 43, no. 16, pp. 8417-8425, 2016.

[25] L. Griffiths, O. Lengliné, M. J. Heap, P. Baud, and J. Schmittbuhl, "Thermal cracking in Westerly Granite monitored using direct wave velocity, coda wave interferometry, and acoustic emissions," Journal of Geophysical Research: Solid Earth, vol. 123, no. 3, pp. 2246-2261, 2018.

[26] M. H. B. Nasseri, A. Schubnel, and R. P. Young, "Coupled evolutions of fracture toughness and elastic wave velocities at high crack density in thermally treated Westerly granite," International Journal of Rock Mechanics and Mining Sciences, vol. 44, no. 4, pp. 601-616, 2007.

[27] S. Vinciguerra, C. Trovato, P. G. Meredith, and P. M. Benson, "Relating seismic velocities, thermal cracking and permeability in Mt. Etna and Iceland basalts," International Journal of Rock Mechanics and Mining Sciences, vol. 42, no. 7-8, pp. 900-910, 2005. 